\title{
OTIMIZAÇÃO E CARACTERIZAÇÃO DE MICROPARTÍCULAS DE QUITOSANA IMOBILIZADA EM LIPASE PANCREÁTICA COMERCIAL
}

Renan Cabral COGNETTE ${ }^{1}$

Ernandes Benedito PEREIRA ${ }^{2}$

\begin{abstract}
${ }^{1}$ Graduado em Biotecnologia, Universidade Federal de Alfenas, UNIFAL-MG, Laboratório de Bioprocessos, email: renan_cognette@hotmail.com

${ }^{2}$ Universidade Federal de Alfenas, UNIFAL-MG, Campus Sede, Departamento de Alimentos e Medicamentos, Laboratório de Bioprocessos, Rua Gabriel Monteiro da Silva, 700, Centro, Alfenas, 37130-000, email: ernandes.pereira@ unifal-mg.edu.br
\end{abstract}

Recebido em: 09/11/2016 - Aprovado em: 05/01/2017 - Disponibilizado em: 01/07/2017

\begin{abstract}
RESUMO
A aplicação de enzimas em atividades industriais vem crescendo dia a dia, tornando-se indispensável para processos como tratamentos contínuos, controle automatizado, melhoria dos rendimentos por unidade de enzima, obtenção de derivados mais puros e diminuição de necessidades energéticas, entre outras. Como a utilização de enzimas nativas apresenta limitações, por exemplo, o alto custo, pode-se optar pela imobilização de biocatalisadores a fim de minimizar tais limitações, proporcionando altos rendimentos industriais. Dentre os suportes utilizados na imobilização, destacamse polímeros naturais de baixo custo e de fácil obtenção, como a quitosana, usada no preparo de partículas para diferentes propósitos, o que permite, dentre outras vantagens, incrementarem as cinéticas de adsorção e promover maior facilidade de manuseio e operação. Neste trabalho foram testadas diferentes concentrações de quitosana, sendo as micro e/ou nanopartículas analisadas morfologicamente por microscopia eletrônica de varredura (MEV). Além disso, foram realizadas a caracterização físico-química e a determinação da atividade da enzima livre e imobilizada. A tecnologia de imobilização de lipases em partículas de quitosana tem sido alvo de muitas investigações visando aperfeiçoar a obtenção de produtos de interesse biotecnológico, abrindo novas perspectivas de mercado.
\end{abstract}

Palavras-chaves: Imobilização. Micropartículas. Quitosana. Lipase. Hidrólise.

\begin{abstract}
The application of enzymes in industrial activities is growing up day by day, making it essential for processes such as continuous treatments, automated control, and improvement of the productivity per unit of enzyme, obtaining derivatives that are more pure and reduction of the energy needs, among others. Because the use of native enzymes has limitations, for example, the high cost, one can opt for immobilizing these biocatalysts to minimize this particular limitation, providing high industrial yields. Among the supports used in immobilization, it stands out the inexpensive natural polymers and easy to obtain, as the chitosan used in the preparation of particles for different purposes, allowing, among other advantages, the scaling up of the kinetics for adsorption and promoting easier handling and operation. In this work, it was tested different concentrations of chitosan, and the micro and / or nanoparticles were analyzed morphologically by scanning electron microscopy (SEM). In addition, there were the physical and chemical characterization and the determination of the activity of free and immobilized enzyme. The lipases immobilization technology in chitosan particles has been the subject of many investigations aiming to improve the production of products of biotechnological interest, opening up new market prospects.
\end{abstract}

Keywords: Immobilization. Microparticles. Chitosan. Lipase. Hydrolysis. 


\section{Introdução}

A utilização de enzimas como catalisador evoluiu expressivamente nos últimos anos. Isso é uma decorrência direta do desafio imposto a nós de termos uma sociedade moderna baseada na combinação do desenvolvimento econômico e a preservação do meio ambiente. Características tais como: alta eficiência catalítica, alto grau de especificidade e a capacidade de acelerar reações químicas específicas sem a formação de subprodutos indesejáveis são aspectos que contribuem para o emprego acelerado destes biocatalisadores em todos os campos da indústria (SILVA, 2014).

Mais de 4000 enzimas são conhecidas e aproximadamente 200 são utilizadas comercialmente, sendo a grande maioria de origem microbiana. Pelo menos $75 \%$ de todas as enzimas industrializadas são hidrolases e destas, 90\% são produzidas por microorganismos através de processos fermentativos. Depois das proteases e carboidrases, as lipases vêm conquistando um espaço crescente no mercado de enzimas, devido a sua vasta aplicação industrial e constituem o terceiro maior grupo em vendas no mundo (SHARMA; CHISTI; BANERJEE, 2001; AGNOL, 2013). O potencial de uso industrial das lipases é destacado pela versatilidade em processos hidrolíticos e de síntese (GHANDI, 1997). Além disso, as lipases possuem especificidade comprovada, fornecendo produtos que não poderiam ser obtidos por processos químicos convencionais. Esta habilidade catalítica tem sido aplicada na modificação de óleos e gorduras, síntese de compostos orgânicos, suplementos de detergentes, procedimentos analíticos, tratamento de resíduos ricos em gordura, entre outras (SAXENA et al., 1999).

Idealmente sistemas catalisados por lipases devem ser tratados caso a caso e generalizações devem ser praticadas com cautela. Os maiores obstáculos na competição deste processo com a prática corrente da síntese química são: o alto custo dos biocatalisadores e sua baixa estabilidade térmica. Uma maneira de superar tais limitações é proteger a configuração nativa da enzima por meio de sua insolubilização em suportes sólidos. A imobilização da enzima tem um efeito benéfico na sua estabilidade, em função das interações físicas e químicas entre o suporte e as moléculas da enzima. A imobilização, também auxilia na dispersão homogênea da enzima no meio, o que é essencial, para a condução de reações enzimáticas (GOMES et al., 2006).

O objetivo do presente trabalho foi imobilizar a lipase comercial (extraída do pâncreas de porco) em micropartículas de quitosana, utilizando glutaraldeído como agente ativador, visando obter uma maior razão de imobilização da enzima. 


\section{Procedimentos experimentais}

Reagentes

Foi utilizada lipase comercial, de origem pancreática, adquirida comercialmente da Sigma Aldrich. Como material de partida foi utilizado o azeite de oliva (substrato padrão). Demais reagentes como solventes (ácido acético, acetona, álcool etílico); sais (fosfato dibásico de potássio, fosfato monobásico de potássio); emulsificantes (goma arábica); bases (hidróxido de potássio e hidróxido de sódio) foram adquiridas de marcas comerciais.

Preparação das micropartículas de quitosana

Quitosana $(2,5 \%)$ foi dissolvida em ácido acético a 5,0\%, de acordo com KIMURA et al. (1999) e então, gotejada em uma solução básica de hidróxido de sódio 1M. Após 5 minutos, a solução foi filtrada a vácuo e em seguida removida do papel de filtro. Para cada grama de suporte foi adicionado $1,5 \mathrm{~mL}$ de glutaraldeído e deixado em repouso por 24h. Após este período, as micropartículas estavam prontas para adsorção enzimática.

Preparação da adsorção enzimática ao suporte

Foi preparada uma solução enzimática de $20 \mathrm{mg} \cdot \mathrm{mL}^{-1}$ e colocada em contato com o suporte preparado anteriormente. Após o período de $24 \mathrm{~h}$, a solução foi filtrada a vácuo. A parte sólida (derivado imobilizado) foi utilizada nos experimentos de imobilização e o filtrado utilizado para dosagem de proteínas (BRADFORD, 1976).

Ativação do suporte

O suporte foi embebido em solução de agente de ativação (glutaraldeído) 2,5\% (v/v) em tampão fosfato de sódio $0,1 \mathrm{M}(\mathrm{pH} 7,0)$, na proporção massa de suporte: volume de solução de 1:10, sendo esta mistura mantida sob agitação por $1 \mathrm{~h}$ à temperatura ambiente. Após este período, o suporte foi lavado exaustivamente com água destilada e em seguida levado à estufa $\left(60^{\circ} \mathrm{C}\right)$ por $24 \mathrm{~h}$.

Caracterização das nanopartículas e/ou micropartículas

Análise morfológica através de microscopia eletrônica de varredura

A análise morfológica (superfície e forma) das nano e/ou micropartículas foi realizada através de microscopia eletrônica de varredura (MEV) (Jeol Scanning Microscope, JSM-5800). As nano ou micropartículas foram previamente metalizadas com ouro (Jeol Jee 4B SVG-IN).

Determinação da atividade hidrolítica em função do tempo

A determinação da atividade da enzima livre e da enzima imobilizada foi realizada por titulação conforme SOARES et. 
al., 1999. À solução enzimática foi acrescido o substrato em forma de emulsão e o tampão fosfato de sódio $0,1 \mathrm{M}(\mathrm{pH} 7,0)$. Tal substrato foi obtido através da emulsão de azeite de oliva com solução de goma arábica a $7 \%$ $\left(\mathrm{m} \cdot \mathrm{v}^{-1}\right)$. A solução foi mantida sob agitação à $37^{\circ} \mathrm{C}$ durante 5 minutos. A determinação da atividade enzimática foi realizada através da titulação com $\mathrm{KOH}$ 0,02 M. A fim de cessar a reação catalisada pela enzima, foi adicionada uma solução de álcool/acetona (1:1). A partir dos volumes de base gastos na titulação, foi calculada a atividade enzimática, em $\mu$ mol.min ${ }^{-1} \cdot \mathrm{mg}^{-1}$ de acordo com a seguinte fórmula:

$$
U=\frac{\left(V_{A}-V_{B}\right) \cdot M \cdot 1 \cdot 10^{6}}{t \cdot m}
$$

Onde: $\mathrm{U}=$ Atividade enzimática; $\mathrm{V}_{\mathrm{A}}=$ Média dos volumes de titulação para frascos com solução enzimática; $V_{\mathrm{B}}=$ Média dos volumes de titulação para frascos com o branco; $\mathrm{M}=$ Molaridade; $\mathrm{t}=$ tempo em minutos $\mathrm{da}$ reação enzimática; $m$ = massa da enzima não pura em miligramas.

\section{Caracterização físico-química da lipase}

A influência do $\mathrm{pH}$ e temperatura nas atividades de ambas as enzimas, livre e imobilizada, foram estudadas utilizando-se a reação de hidrólise na faixa de $\mathrm{pH}$ entre 5 a 8 , e nas temperaturas de 30 a $60^{\circ} \mathrm{C}$. O efeito da temperatura na estabilidade da lipase livre e imobilizada foi determinado por meio da incubação das enzimas a 37 e $50^{\circ} \mathrm{C}$ em tampão fosfato de sódio $0,1 \mathrm{M}(\mathrm{pH} 7,0)$ durante 120 minutos. Em intervalos de 30 minutos, foram retiradas as amostras as quais foram imediatamente resfriadas em banho de gelo para interromper a reação de inativação. Em seguida, a atividade residual foi determinada a $37^{\circ} \mathrm{C}$, pela adição de $5,0 \mathrm{~mL}$ de emulsão de azeite de oliva. As constantes de desativação $\left(\mathrm{Kd}, \mathrm{h}^{-1}\right)$ e o tempo de meia-vida foram calculadas, analisando-se a atividade enzimática inicial e a atividade residual após tratamento térmico durante um certo período de incubação $(\mathrm{t})$, de acordo com a equações 1 e 2 .

$$
\ln A=\ln A o-K d * t
$$

Onde: $\mathrm{A}_{0}=$ atividade enzimática inicial; $\mathrm{A}=$ atividade residual após tratamento térmico durante certo período de incubação (t).

$$
\mathrm{t}_{1 / 2}=0,693 / \mathrm{K}_{\mathrm{d}}
$$

\section{Resultados e Discussão}

\section{Principais ácidos graxos componentes dos óleos}

Nas Tabelas 1 a 5 estão descritos os principais ácidos graxos componentes de cada óleo utilizado neste estudo e abaixo o cálculo da massa molar a ser utilizada para determinar a razão molar da reação. 
Tabela 1 - Composição em ácidos graxos do óleo de algodão.

\begin{tabular}{|l|c|c|c|}
\hline \multicolumn{1}{|c|}{ Ác. Graxo } & $\begin{array}{c}\% \\
(\mathbf{m} / \mathbf{m})\end{array}$ & $\begin{array}{c}\text { Massa } \\
\text { Molar }\end{array}$ & $\begin{array}{c}\text { MM } \\
\text { parcial }\end{array}$ \\
\hline $\mathrm{C}_{14: 0}$ (mirístico) & 1,0 & 228,37 & 228,37 \\
\hline $\mathrm{C}_{16: 0}$ (palmítico) & 25,0 & 256,42 & 6410,5 \\
\hline $\mathrm{C}_{18: 0}$ (esteárico) & 2,8 & 284,47 & 796,516 \\
\hline $\mathrm{C}_{18: 1}$ (oléico) & 17,1 & 282,46 & 4830,066 \\
\hline $\mathrm{C}_{18: 2}$ (linoléico) & 52,7 & 280,44 & 14779,186 \\
\hline
\end{tabular}

$\left.\mathbf{M M}_{\mathrm{AC}}=\sum\left(\%_{\mathrm{i}} \mathrm{x} \mathrm{Mmi}\right) / \sum \% \mathrm{i}\right)=27044,636 / 98,6=$

\section{4,29 g/mol}

$\mathbf{M M}_{\text {óleo }}=3\left(\mathrm{MM}_{\mathrm{AC}}\right)+38=\mathbf{8 6 0 , 8 6} \mathbf{~ g} / \mathbf{m o l}$

Tabela 2 - Composição em ácidos graxos do óleo de canola.

\begin{tabular}{|c|c|c|c|}
\hline Ác. Graxo & $\begin{array}{c}\% \\
(\mathbf{m} / \mathbf{m})\end{array}$ & $\begin{array}{c}\text { Massa } \\
\text { Molar }\end{array}$ & $\begin{array}{c}\text { MM } \\
\text { parcial }\end{array}$ \\
\hline $\mathrm{C}_{16: 0}$ (palmítico) & 3,75 & 256,42 & 961,58 \\
\hline $\mathrm{C}_{18: 0}$ (esteárico) & 1,87 & 284,47 & 531,96 \\
\hline $\mathrm{C}_{18: 1}$ (oléico) & 62,41 & 282,46 & 17628,33 \\
\hline $\mathrm{C}_{18: 2}$ (linoléico) & 20,12 & 280,44 & 5642,45 \\
\hline $\mathrm{C}_{18: 3}$ (linolênico) & 8,37 & 278,42 & 2330,38 \\
\hline $\mathrm{C}_{20: 1}$ (eicosenóico) & 1,54 & 310,52 & 478,20 \\
\hline
\end{tabular}

$\left.\mathbf{M M}_{\mathrm{AC}}=\sum\left(\%_{\mathrm{i}} \times \mathrm{Mmi}\right) / \sum \% \mathrm{i}\right)=27572,5 / 98,06=$ 281,18 g/mol

$\mathbf{M M}_{\text {óleo }}=3\left(\mathrm{MM}_{\mathrm{AC}}\right)+38=\mathbf{8 8 1 , 5 5} \mathbf{g} / \mathbf{m o l}$

Tabela 3 - Composição em ácidos graxos do óleo de girassol.

\begin{tabular}{|c|c|c|c|}
\hline Ác. Graxo & $\begin{array}{c}\% \\
(\mathbf{m} / \mathbf{m})\end{array}$ & $\begin{array}{c}\text { Massa } \\
\text { Molar }\end{array}$ & $\begin{array}{c}\text { MM } \\
\text { parcial }\end{array}$ \\
\hline $\mathrm{C}_{16: 0}$ (palmítico) & 5,70 & 256,42 & 1461,59 \\
\hline $\mathrm{C}_{18: 0}$ (esteárico) & 4,79 & 284,47 & 1362,61 \\
\hline $\mathrm{C}_{18: 1}$ (oléico) & 15,26 & 282,46 & 4310,34 \\
\hline $\mathrm{C}_{18: 2}$ (linoléico) & 71,17 & 280,44 & 19958,91 \\
\hline $\mathrm{C}_{22: 0}$ (behênico) & 1,16 & 340,59 & 395,08 \\
\hline
\end{tabular}

$\left.\mathbf{M M}_{\mathrm{AC}}=\sum\left(\%{ }_{\mathrm{i}} \mathrm{x} \mathrm{Mmi}\right) / \sum \% \mathrm{i}\right)=27488,53 / 98,06=$

280,32 $\mathrm{g} / \mathrm{mol}$

$\mathbf{M M}_{\text {óleo }}=3\left(\mathrm{MM}_{\mathrm{AC}}\right)+38=\mathbf{8 7 8 , 9 6} \mathbf{g} / \mathbf{m o l}$

Tabela 4 - Composição em ácidos graxos do óleo de soja.

\begin{tabular}{|c|c|c|c|}
\hline Ác. Graxo & $\begin{array}{c}\% \\
(\mathbf{m} / \mathbf{m})\end{array}$ & $\begin{array}{c}\text { Massa } \\
\text { Molar }\end{array}$ & $\begin{array}{c}\text { MM } \\
\text { parcial }\end{array}$ \\
\hline $\mathrm{C}_{16: 0}$ (palmítico) & 10,82 & 256,42 & 2774,47 \\
\hline $\mathrm{C}_{18: 1}$ (oléico) & 24,18 & 282,46 & 6829,88 \\
\hline $\mathrm{C}_{18: 2}$ (linoléico) & 52,72 & 280,44 & 14784,80 \\
\hline $\mathrm{C}_{18: 3}$ (linolênico) & 6,56 & 278,42 & 1826,44 \\
\hline
\end{tabular}

$\left.\mathbf{M M}_{\text {AC. }}=\sum\left(\% \%_{\mathrm{i}} \times \mathrm{Mmi}\right) / \sum \% \mathrm{i}\right)=26215,59 / 94,28=$ 278,06 g/mol

$\mathbf{M M}_{\text {óleo }}=3\left(\mathrm{MM}_{\mathrm{AC}}\right)+38=\mathbf{8 7 2 , 1 8} \mathbf{g} / \mathbf{m o l}$
Tabela 5 - Composição em ácidos graxos do óleo de café.

\begin{tabular}{|c|c|c|c|}
\hline Ác. Graxo & $\%(\mathbf{m} / \mathbf{m})$ & $\begin{array}{c}\text { Massa } \\
\text { Molar }\end{array}$ & $\begin{array}{c}\text { MM } \\
\text { parcial }\end{array}$ \\
\hline $\begin{array}{c}\mathrm{C}_{16: 0} \\
\text { (palmítico) }\end{array}$ & 10,90 & 256,42 & 2794,98 \\
\hline $\mathrm{C}_{18: 1}$ (oléico) & 26,23 & 282,46 & 7408,93 \\
\hline $\begin{array}{c}\mathrm{C}_{18: 2} \\
\text { (linoléico) }\end{array}$ & 51,00 & 280,44 & 14302,44 \\
\hline $\begin{array}{c}\mathrm{C}_{18: 3} \\
\text { (linolênico) }\end{array}$ & 6,56 & 278,42 & 1826,44 \\
\hline
\end{tabular}

$\mathbf{M M}_{\mathrm{AC}}=\sum\left(\%{ }_{\mathrm{i}} \mathrm{x}\right.$ Mmi $\left.) / \sum \% \mathrm{i}\right)=26332,79 / 94,69=$ 278,09 $\mathrm{g} / \mathrm{mol}$

$\mathbf{M M}_{\text {óleo }}=3\left(\mathrm{MM}_{\mathrm{AC}}\right)+38=\mathbf{8 7 2 , 2 8} \mathbf{g} / \mathbf{m o l}$

\section{Viscosidade e densidade dos óleos}

A Tabela 6 mostra os resultados das análises de densidade, viscosidade (cP) e viscosidade cinemática (cSt) dos óleos e ésteres etílicos produzidos.

Tabela 6 - Propriedades dos óleos e do biodiesel obtido.

\begin{tabular}{|c|c|c|c|}
\hline Amostra & $\begin{array}{c}\text { Densidade } \\
(\mathbf{g} / \mathbf{m L})\end{array}$ & $\begin{array}{c}\text { Viscosidade } \\
\text { (cP) }\end{array}$ & $\begin{array}{c}\text { Viscosidade } \\
\text { Cinemática } \\
\text { (cSt) }\end{array}$ \\
\hline Soja (óleo) & 0,91 & 32,47 & 35,68 \\
\hline $\begin{array}{c}\text { Girassol } \\
\text { (óleo) }\end{array}$ & 0,91 & 29,10 & 31,98 \\
\hline $\begin{array}{c}\text { Canola } \\
\text { (óleo) }\end{array}$ & 0,90 & 33,60 & 37,33 \\
\hline $\begin{array}{c}\text { Algodão } \\
\text { (óleo) }\end{array}$ & 0,91 & 30,25 & 33,24 \\
\hline Café (óleo) & 0,91 & 32,98 & 36,24 \\
\hline $\begin{array}{c}\text { Soja } \\
\text { (biodiesel) }\end{array}$ & - & 4,40 & 4,83 \\
\hline $\begin{array}{c}\text { Girassol } \\
\text { (biodiesel) }\end{array}$ & - & 3,52 & 3,87 \\
\hline $\begin{array}{c}\text { Canola } \\
\text { (biodiesel) }\end{array}$ & - & 3,59 & 3,99 \\
\hline $\begin{array}{c}\text { Algodão } \\
\text { (biodiesel) }\end{array}$ & - & 3,89 & 4,27 \\
\hline $\begin{array}{c}\text { Café } \\
\text { (biodiesel) }\end{array}$ & - & 4,70 & 5,13 \\
\hline
\end{tabular}

Os resultados evidenciam uma conversão eficiente dos triglicérideos para ésteres etílicos, pois os mesmos passaram a 
ter um valor de viscosidade cinemática que se enquadra em um intervalo ideal para utilização do biodiesel, entre 3,5 e 5,5 centiStokes.

\section{Teor de umidade e atividade hidrolítica do} imobilizado enzimático

A umidade do preparado foi devidamente avaliada em aparelho específico, atingindo $10,53 \%$ de umidade em relação a massa total do imobilizado, um valor dentro do que se esperava para que as enzimas trabalhassem bem na conversão e a reação ocorresse bem. A Tabela 7 mostra os resultados da análise de atividade hidrolítica, em unidades de atividade por grama (U/g), da enzima AK de Pseudômonas fluorescens imobilizada em suporte POS-PVA.

Tabela 7 - Atividade hidrolítica do imobilizado enzimático.

\begin{tabular}{|c|c|c|c|}
\hline \multicolumn{4}{|c|}{ Massa úmida (g) } \\
\hline Amostra 1 & Amostra 2 & Amostra 3 & Média \\
\hline $\mathbf{1 8 6 8 , 4 4}$ & $\mathbf{1 9 6 3 , 1 0}$ & $\mathbf{1 9 6 0 , 4 3}$ & $\mathbf{1 9 3 0 , 6 5}$ \\
\hline \multicolumn{4}{|c|}{ Massa Seca (g) } \\
\hline $\mathbf{1 6 7 1 , 7 0}$ & $\mathbf{1 7 5 6 , 3 8}$ & $\mathbf{1 6 7 1 , 7 0}$ & $\mathbf{1 7 5 6 , 3 8}$ \\
\hline
\end{tabular}

A atividade da massa seca foi calculada descontando-se o teor de umidade das amostras. Os valores de atividade hidrolítica alcançado pelas enzimas imobilizadas foram bastante satisfatórios, considerando que ao ser imobilizado uma parcela das enzimas fica inserida no suporte, diminuindo sua superfície de contato com o substrato e consequentemente sua atividade.

\section{Análise cromatográfica dos produtos obtidos}

A análise de cromatografia gasosa das amostras de biodiesel obtidas foi realizada pra determinar a conversão de cada ácido graxo presente nos óleos, de forma que foi possível acompanhar a reação ao longo do tempo, como mostrado na Figura 1, para cada um dos óleos estudados.

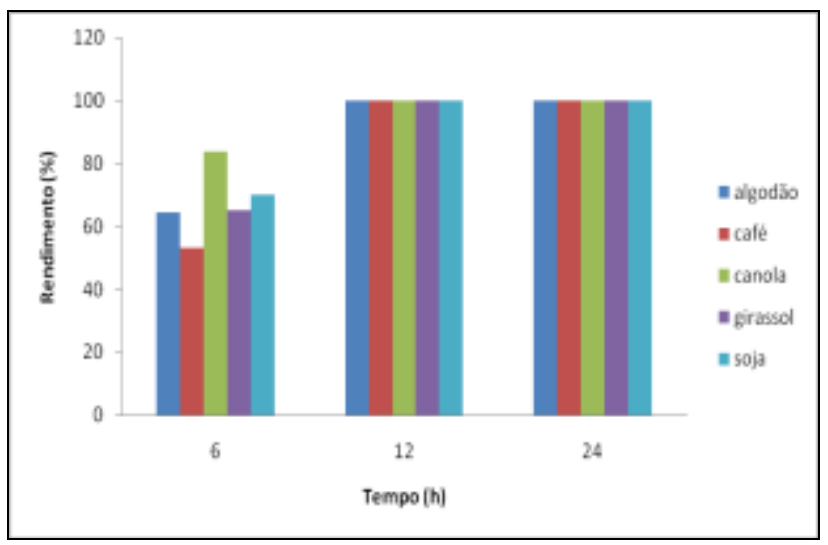

Figura 1 - Rendimento da conversão dos óleos em biodiesel ao longo do tempo.

O rendimento avaliado aos tempos de 48 e $72 \mathrm{~h}$ foi omitido, pois foi observado que aos tempos de 12 e $24 \mathrm{~h}$ o rendimento já havia atingido $100 \%$ de conversão dos óleos em biodiesel.

Pôde-se observar um tempo e rendimento de conversão bastante satisfatório por se tratar de uma reação enzimática, destacando-se o óleo de canola que apresentou maior rendimento ao tempo de 6 horas. O óleo de café, apesar de não ter se destacado na primeira medição, também 
apresentou rendimento de $100 \%$ ao final de 12 horas, provando ser uma matéria prima interessante para a produção de biodiesel no Brasil.

\section{CONCLUSÃO}

Com base nos dados obtidos neste estudo, podemos afirmar que a via enzimática está muito próxima da eficiência da via química para converter óleos vegetais em biodiesel. Além disso, as vantagens observadas em um processo de catálise enzimática são muito superiores, tendo maior facilidade na separação do catalisador e dos subprodutos, maior aproveitamento dos óleos, pois as enzimas são mais específicas que os catalisadores químicos, e futuramente, esperase que o custo deste processo se torne menor com o reaproveitamento das enzimas imobilizadas em diversas bateladas ou processo contínuo.

Outro ponto interessante a se observar neste estudo é que a diversidade de óleos vegetais que podem ser utilizados na produção de biodiesel é bastante eficiente, utilizando-se o mesmo álcool e o mesmo catalisador enzimático, mostrando que uma produção em maior escala não ficaria necessariamente dependente de apenas uma espécie oleaginosa.

\section{AGRADECIMENTOS}

Ao PIBIC/ CNPq pela bolsa de Iniciação Científica, a UNIFAL-MG e a EEL/USP.

\section{REFERÊNCIAS}

ABRIGOR, R.D., UADIA, P.O., FOGLIA, T.A., et al. Lipase-catalysed production of biodiesel fuel from some Nigerian lauric oils. Biochemical Society Transactions (2000), Volume 28, part 6.

BAN, K., HAMA, S., NISHIZUKA, K., KAIEDA M., MATSUMOTO, T., KONDO, A., NODA, H., FUKUDA, H, Repeated use of whole-cell biocatalysts immobilized within biomass support particles for biodiesel fuel production. Journal of Molecular Catalysis

B: Enzymatic 17 (2002) 157-165, 2002. 17: p. $157-165$.

CANAKCI, M.; VAN GERPEN, J.; Trans. ASAE 2001, 44, 1429.

D’AGOSTO, M.A. (2004) Análise da Eficiência da Cadeia Energética para as Principais Fontes Utilizadas em Veículos Rodoviários no Brasil. Tese de Doutorado, PET-COPPE-UFRJ, Rio de Janeiro. Apud: DERALDO, J. M. M. BIODIESEL, A ALTERNATIVA ENERGÉTICA BRASILEIRA PARA O SETOR DE TRANSPORTES PÚBLICO E DE CARGAS. 2006 Dissertação de Mestrado. UFRJ.

DERALDO, J. M. M. BIODIESEL, A ALTERNATIVA ENERGÉTICA BRASILEIRA PARA O SETOR DE TRANSPORTES PÚBLICO E DE CARGAS. 2006. Dissertação de Mestrado. UFRJ.

DIZGE, N., KESKINLER, B., 2008. ENZYMATIC PRODUCTION OF BIODIESEL FROM CANOLA OIL USING IMMOBILIZED LIPASE. Biomass

Bioenergy. 32, 1274-1278. 
ENCINAR, J. M.; GONZÁLEZ, J. F.; SABIO, E.; RAMIRO, M. J.; Ind. Eng.

Chem. Res. 1999, 38, 2927.

FARMACOPÉIA BRASILEIRA 4. ed.: São Paulo, 2004.

FERRARI, R. A., OLIVEIRA, V. S., SCABIO, A. Biodiesel fromsoybean: characterization and consumption in anenergygenerator. Quím. Nova, Jan./Feb. 2005, vol.28, no. 1, p.19-23. ISSN 01004042.

FREITAS, C., BREMNER, S. A., GOUVEIA, $\mathrm{N}$ et al. Internações e óbitos e sua relação com a poluição atmosférica em São Paulo, 1993 a 1997. Rev. Saúde Pública, Dez. 2004, vol. 38, no. 6, p. $751-757$. ISSN 0034-8920.

GUIEYSSE, D., SALAGNAD, C., MONSANA, P., REMAUD-SIMEONA, M.,Lipase-Catalyzed Enantioselective Transesterification Toward Esters Of 2Bromo-Tolylacetic Acids. Tetrahedron: Asymmetry 14 (2003) 317-323, 2003. 14: p. 317-323.

HAAS, M.J., PIAZZA, G.J., FOGLIA, T.A., Enzymatic approaches to production of biodiesel fuels. In: Kuo, T.M., Gardner, H.W. (Eds), Lipids Biotechnology. Marcel Dkker, New York, USA, Chapter 29. 2002

HERNANDEZ-MARTIN, E., OTERO, C., 2008. Different enzyme requirements for the synthesis of biodiesel: Novozym 435 and Lipozyme TL IM. Bioresour. Technol. 99, 277-286

LIMA, J. R. O., SILVA, R. B., SILVA, C. C. M. et al. Biodiesel from babassu (Orbignya sp.) synthesized via ethanolic route.

Quím.Nova, May/June 2007, vol.30, no.3, p.600-603.ISSN 0100-4042.

MACEDO, G. A.; MACEDO, J. A. Produção de biodiesel por transesterificação de óleos vegetais. Biotecnologia Ciência e

Desenvolvimento, N. 32, P. 38-46, 2004.

NASCIMENTO, M. G.; COSTA NETO, P. R.; MAZZUCO, L. M.; Biotecnologia

Ciência \& Desenvolvimento2001, 19, 28. OLIVEIRA, D., OLIVEIRA, J.V., FACCIO, C. et al. Evaluation of the influence of process variables on enzimaticalcoholysis of castor oil.Ciênc.Tecnol.Aliment., Apr./June 2004, vol.24, no.2, p.178-182. ISSN 01012061.

PINTO, A. C., GUARIEIRO, L. L. N., REZENDE, M. J. C.et al. Biodiesel: an overview.J. Braz. Chem. Soc., Nov./Dec. 2005, vol.16, no.6b, p.1313-1330. ISSN 0103-5053.

RAMOS, L. P.; DOMINGOS, A. K.; KUCEK, K. T.; WILHELM, H. M. Biodiesel: Um projeto de sustentabilidade econômica e sócio-ambiental para o Brasil. Biotecnologia: Ciência e Desenvolvimento, v.31, p.28-37, 2003.

SHARMA, Y.C., SINGH, B., 2008.

Development of biodiesel from karanja, a tree found in rural India.Fuel 87, 1740-1742.

SHIMADA, Y., WATANABE, Y., SAMUKAWA, T., 1999. Conversion of vegetable oil tobiodiesel using immobilized Candida antarctica lipase. J. Am. Oil Chem. Soc. 76, 789-793

VALLIKIVI, I., LILLE, U., LOOKENE, A., METSALA, A., SIKK, P., TÕUGU, V., VIJA, H., VILLO, L., PARVE, O., Lipase Action On Some Non-Triglyceride Substrates. Journal of Molecular Catalysis B: Enzymatic 22 (2003) 279-298, 2003. 22: p. 279-298. 